\title{
The Development of Theory in Accounting Research
}

\author{
Melissa Aldredge ${ }^{1}$, Glen Cooley ${ }^{2}$, Temberlee Mallett ${ }^{3}$ \\ ${ }^{1,2}$ College of Business and Technology,Northwestern State University,Natchitoches \\ ${ }^{3}$ Emerging Leader Managerial Program,GEICO,Richardson
}

\begin{abstract}
Accounting is a field that operates within an ever-changing environment. In terms of accounting research, development of theory is a central activity crucial to the advancement of knowledge within the discipline. To aid in the development of accounting information, standard setting bodies have developed a foundation of concepts embodied within a conceptual framework. This paper explores the literature related to theories used in accounting research, and provides commentary on the contributions made by the Financial Accounting Standards Board's Conceptual Framework Project.
\end{abstract}

Keywords: accounting research, accounting theory, conceptual framework, CFP, behavioral research theory, Agency theory

\section{Introduction}

Accounting is a field that operates within an ever-changing environment.Accounting professionals and users of financial information constantly lobby for and stress the importance of accurate and transparent accounting.Standard setting bodies, primarily the Financial Accounting Standards Board (FASB), have responded to this need by implementing a uniform set of standards to guide users. While these standards have contributed to the growth of the profession, it is a struggle to keep them updated with evolving business and economic advances without compromising their integrity. To combat this, FASB developed a foundation of concepts that would not only sustain the integrity of accounting standards, but also aid in further research used to support theories on the uses of accounting information.This paper provides commentaryon the development of FASB's conceptual framework,and uses supporting scholarly literature to discuss research methodologies, mainstream theoretical views, and subsequent modifications to theories used in accounting research.

\section{The Conceptual Framework Project}

\section{The Development of Theory in Accounting Research}

Since the thrust of this paper centers on research methodologies and theory development, only a brief explanation of the Conceptual Framework Project (CFP) will be given to provide the reader with a context to understand the fundamental elements and contributions the CFP provides. The FASB conceptual framework is best summarized as the compilation of Statements of Financial Accounting Concepts (SFAC)numbers five, six, and eight. It should be understood that SFACs are not pronouncements that enforce rules 203 or 204 of the Code of Professional Ethics and serve mainly to improve communications, promote consistency, and reduce bias in standard setting. Schroeder, Clark, and Cathey (2014) divide the Conceptual Framework Project (CFP) into three levels.

Level one of the CFP establishes the foundation and identifies the main objective of financial reporting is to provide, "financial information about the reporting entity that is useful to current and potential equity investors, lenders, and other creditors in making decisions about providing resources to the entity" (Schroeder et al., 2014, p. 49). The main importance of this element is that it provides the board with an explicit definition of the end users who will apply the standards it sets.Level one is entirely composed of the SFAC No. 8 and goes on to describe the cost constraint that accompanies financial reporting. Essentially, the cost constraint is the issue faced by entities in deciding whether the costs that go into issuing financial information are outweighed by the benefits provided and the issue faced by users in determining if the costs of obtaining financial information about an entity are outweighed by the benefits of using it (Schroeder et al., 2014). This constraint is critical to the CFP because it gives rise to the second level of the framework that determines what exactly makes accounting information useful, or beneficial, to the users defined in SFAC No.8.Level two focuses more on the qualitative characteristics of the CFP and is jointly composed of the SFACs No. 5, No. 6, and No. 8. SFAC No. 8 describes that benefit is determined by information having the qualities of being both relevant and faithfully represented. SFAC No. 6 contributes to the framework by defining the ten measurement and performance elements - assets, liabilities, equity, investments by owners, distributions to owners, comprehensive income (explicitly defined in SFAC No.5), revenues, expense, gains, and losses. Collectively, Schroeder et al. (2014) labels these elements as the "building blocks" of financial statement construction. Level three of the CFP deals with the implementation guidelines used in recognizing, measuring, and disclosing accounting information and is carried out through assumptions, principles, and constraints. The CFP was the leading accounting theory at 
the time of its introduction,but explained more of what accounting information should be used as opposed to how accounting information was used. By recognizing the components of the CFP and identifying the flaws associated with it, a consensus can be reached in the need to first understand research methodologies applied to identify the use of accounting information, and second to examine theories surrounding the reactions to accounting information.

\section{Research Methodologies and Accounting Theory}

Schroeder et al. (2014) details five research methodologies (deductive, inductive, pragmatic, ethical, and behavioral)which are used to develop theory. All of these approaches have in some form directly or indirectly given rise to specific accounting theories. In early research, Carl Devine put great effort into stressing the need for ethical considerations in theory development. Devine (1960) used the term "welfare-accounting" specifically; however, modern terminology refers to it as the ethical approach. Both terms hold origins with the works of renowned D. R. Scott and for the purposes of this paper hold equal meaning. The ethical approach places emphasis on truth, justice, and fairness (Schroeder et al., 2014). Devine (1960) cautioned that, "...the accountant must look to the accepted social standard of the place and time and use existing social attitudes as they are expressed in the form of laws, customs, administrative decisions, religious edicts, and the like, as the basis for subjective decision" (p. 398).

Gaffikin(1988) provides an evaluation of developments in accounting methodology that divides theories into inductive theories (Type A), and deductive theories (Type B). He goes onto subcategorize each type based on nature, structure, and testing. Gaffikin (1988) considered inductive theories to be descriptive in nature, have a notable pragmatic (relational) structure and require empirical verification testing. Deductive theories were normative in nature, syntactic in structure, and require logistical testing (Gaffikin, 1988). The explanation Schroeder et al. (2014) provides describes the deductive approach as being structured around the logical relation and identification of accounting processes to accounting objectives and operational environments. The inductive approach is described as being a generalized observation to conclusion process. These two descriptions are virtually identical, with the exclusion of treatment for the pragmatic view andGaffikin's omissionof the ethical, behavioral, and scientific approaches.Schroeder et al. (2014) ranks the pragmatic approach equal to inductive and deductive approaches and highlights its foundation in the utility concept which serves as the leading approach in current principles and practices.

A behavioral approach to research also emerged during the eighties. Caplan (1989) detailed the approach as encompassing elements of sociological theories toward organizations and psychologists' research toward motivation. He stated that the emphasis of behavioral research, however, was on"an examination of the perceptions, cognitive abilities, and value structures, of decision makers as well as the organizational processes that influence them"(Caplan, 1989, p. 112). The relationship between the individual and organization is a valuable paradigm to view accounting research. However, while the behavioral and ethical approaches have gained more respect within the accounting profession in the last several decades, they areprimarily seen as supportive methods to accounting research rather than independent research methodologies (Schroeder et al., 2014).Agency theory has been a widespread theory used in accounting literature and attempts to explain accounting practices as a whole. Agency theory is an institutional theory derived from a neoclassical economic view of utility maximization as seen from a principal-agent relationship (Hewege, 2012). An agency relationship is defined as one in which a contract exists between one or more persons, the principal or investor, and another person, the agent or firm (Eisenhardt, 1989).Schroeder et al (2014) assigns the central position of agency theory as being the fact that, "individuals maximize their own expected utilities and are resourceful and innovative in doing so" (p. 137). Under this view, conflict will exist between the individual goals of managers and the collective goals of shareholders. The theory concludes by stating that there are multiple methods to account for the same issues because there are multiple individuals with separate end goals in mind (Schroeder et al., 2015).

The foundation of the scientific method of inquiryin research rests highly on identifying a problem and testing a hypothesis. This is contrasted against the above mentioned methods that focus on identifying objectives or observations and drawing conclusions from logical assumptions or generalizations. The scientific method requires tangible data and incorporates statistical methods in its research. It is because of this that the scientific method is often synonymous with empirical research, another hypothesis driven method. Even though having tangible data offers more justifiable conclusions, the scientific approach faces criticisms by professionals. Jones and Wells (2015) compiled warnings from other researchersthat warn of the, "far-fetched" and "detached from reality" nature of its research. They were also skeptical of the lack of replication experiments conducted in the accounting field and compared it to cancer research in the medical field, an issue of importance in society, and the frequent replication and verification of data that field experiences (Jones\&Wells, 2015). Schroeder et al. (2014) also criticized this method for its inability to realistically hold variables constant given the fluctuating nature of the economy.Throughout examinations of the above referenced research, many terms were synonymous and interchangeable. These variations may be contributed to the time period in which these 
generalizations were made and the schools of thought that have evolved throughout history along with technical and institutional advances.Dyckman and Zeff (2015) provide a depiction of changes through time, narrating the shift from normative to empirical approach of accounting research in the 1960s.Dyckman and Zeff (2015) noted that this heavily normative period or "Golden Age" of accounting,"contested whether historical cost, entry value, exit value, [and] 'decision usefulness' should supplant debates over which approaches to valuation should be preferred” (p. 513). Interestingly, the progression of methodologies was influenced considerably by social changes. The increased availability of computers with Compustat and CRSP databases at universities allowed researches to attain data sets needed to test hypothesis used in empirical or scientific research (Dyckman and Zeff, 2015). Subsequently, universities started placing a greater emphasis on behavioral sciences and hypothesis testing. This shift toward empirical research extended so far that the leading accreditation board at the time, American Association of Collegiate Schools of Business, began mandating PhD candidates become knowledgeable in empirical research methodology (Dyckman and Zeff, 2015).

The extensiveness of all of the methodologies may seem overwhelming initially, especially when strictly presented in a comparative and analytical manner. However, it is important to realize that these methodologies extend beyond terms, objectives, and data figures. They have enabled researchers to develop theories widely used in practice today; moreover, theories that, had it not been for specialized methodologies, would not have the proper structure or formulation to still be applicable in current financial environments. For example, the rational market theory, described by Shiller (2003) as the idea that, "speculative asset prices such as stock prices always incorporate the best information about fundamental values and that prices change only because of good, sensible information", became the foundation of national economic policy from 1986 to 2007. This theory began as the efficient market hypothesis (EMH), a widely acceptedconcept that stems from the scientific method of inquiry. The shortcomings of rational market theory were illustrated in the burst of the housing bubble in 2007. The term anomalieswas coined to define events that could not be understood by applying EMH and a new theory, behavioral finance or prospect theory, was created to explain the management of risk and uncertainty (Shiller, 2003). As a result, the capital asset pricing model (CAPM) was developed. Again, scientific methodology accompanied by the supportive behavioral approach was used to pioneer a new way of thinking within the accounting profession.

\section{Conclusion}

In examining the progression of methodologies to working theories, it is often questioned first why there is no one, universal theory that would apply to accounting situations when faced with criticisms and theories that seem to negate each other; and secondly, why these outlooks are still used today. In the most basic reply, this can be attributed to the fluctuating environment of the accounting profession and the end use of accounting information. Perhaps the most forward thinking narrative toward the topic of accounting research and theory is provided by Mary Barth's call for the need to bridge the gap between accounting research and accounting practice. Barth (2015) suggests that, "There are clear benefits of accounting research embracing individuals from different fields with relevant, complementary expertise and knowledge... Their participation in accounting research also reveals new perspectives with which to view nettlesome problems" (p. 504). The input to be provided from other disciplines and other levels of experience and education will create a system that standard setting bodies look to for a more accurate portrayal of accounting information, and more realistic and genuine progressions in the accounting field as a whole, and accounting research in particular.

\section{References}

[1]. Barth, M. E. (2015).Financial accounting research, practice, and financial accountability.Abacus, 51(4), 499-510. doi:10.1111/abac.12057 Retrieved from http://onlinelibrary.wiley.com/doi/10.1111/abac.12057/abstract

[2]. Caplan, E. H. (1989).Behavioral accounting--A personal view.Behavioral Research In Accounting, 1109. Retrieved from http://eds.b.ebscohost.com.ezproxy.nsula.edu/eds/detail

[3]. Devine, C. T. (1960).Research methodology and accounting theory formation. The Accounting Review, (3). 387. Retrieved from http://eds.a.ebscohost.com.ezproxy.nsula.edu/eds/detail

[4]. Dyckman, T. R., \& Zeff, S. A. (2015). Accounting Research: Past, Present, and Future. Abacus, (4), 511. doi:10.1111/abac.12058 Retrieved from http://onlinelibrary.wiley.com/doi/10.1111/abac.12058/abstract

[5]. Eisenhardt, K. M. (1989). Building theories from case study research. Academy of Management

[6]. Review, 14(4), 532. doi:10.5465/AMR.1989.4308385

[7]. Gaffikin, M. (1988). Legacy of the Golden Age: Recent development in the methodology of accounting. Abacus, 24(1), 16-36. Retrieved from http://onlinelibrary.wiley.com/doi/10.1111/

[8]. Hewege, C. R. (2012). A critique of the mainstream management control theory and the way forward. Sage Open, 2(4), doi: 2158244012470114

[9]. Schroeder, R. G., Clark, M. W., \& Cathey, J. M. (2014). Financial accounting theory and analysis:Text and cases (11th ed., pp. 1517). Hoboken, NJ: John Wiley \& Sons, Inc.

[10]. Shiller, R. J. (2003, March 1). From efficient markets theory to behavioral finance [Electronic version]. The Journal of Economic Perspectives, 17(1), 83-104.doi:10.1257/089533003321164967 from http://eds.b.ebscohost.com.ezproxy.nsula.edu/eds/detail

[11]. Jones, S., \& Wells, M. (2015). Accounting research: Wherenow? Abacus, 51(4), 572-586. doi:10.1111/abac.12062 Retrieved from http://eds.b.ebscohost.com.ezproxy.nsula.edu/eds/detail 